\title{
Synthesis, Docking and Anti-cancerous Activity of Some Novel Thiazole Derivatives of Biological Interest
}

\author{
Anitha Ramalingam ${ }^{1, *}$, Sarvanan $\mathrm{J}^{2}$ \\ 'College of Pharmaceutical Sciences, School of Health Sciences, Dayananda Sagar University, Bangalore, Karnataka, INDIA.
}

2Faculty of Pharmaceutical Sciences, PES University, Bangalore, Karnataka, INDIA.

\begin{abstract}
Objectives: Heterocyclic compounds are enormously widespread in nature and have attracted research interest because of their pharmaceutical and biological properties. Amongst the heterocyclic rings, the thiazoles are the most important building blocks in today's drug discovery and are found to have extensive biological activities against different types of diseases. Many potent anti-cancerous drugs like Tiazofurin are having 1,3 thiazole as an active ring structure and based on this theory, a new series of 2, 4 di substituted 1,3 thiazole derivatives were synthesized. Methods: First 2-amino-4-substituted phenyl thiazoles were synthesized by adapting a well-known Hantzsch reaction and subsequently 2-amino substituted derivatives were synthesized using various aryl aldehydes by following established Schiff's reaction. The synthesized compounds were confirmed by TLC, IR, HNMR, CNMR and Mass Spectral Analysis. Then all the synthesized compounds were docked to RAS p21 receptor using PATCH DOCK Software to study their anti-cancerous activity. Then the compounds
\end{abstract}

were screened for cancer cell line studies. Results: All the synthesized compounds exhibited some degree of anti-cancerous activity both in docking studies and in vitro anti-cancerous cell line studies. Conclusion: Amongst all the 16 synthesized, most compounds showed moderate to good anti-cancerous activity and the compounds S3P1c, S3P2c, S3P2d, S3P3a and S3P4d have shown the best activity.

Key words: Thiazole, Hantzsch, Docking, Cancer cell line.

Correspondence

Dr. Anitha Ramalingam

College of Pharmaceutical Sciences, School of Health Sciences, Dayananda Sagar University, Bangalore-560078, Karnataka, INDIA.

Phone no: +91-9902559552

Email: anitramar16@gmail.com

DOI: 10.5330/jpi.2020.4.104

\section{INTRODUCTION}

As per statistics heterocyclic compounds with various positional combinations of hetero atoms like nitrogen, sulphur or oxygen constitute $80 \%$ of the bio-active chemical entities of plants and animals. Heterocyclic rings have very versatile reactivity due to the electronic distribution in the heterocyclic molecules and they can act as anions or cations depending on the $\mathrm{pH}$ of the medium. Their property of high polarity and water solubility leads to their increased bioavailability. 1,3 thiazoles form the considerable group amongst heterocyclic compounds to have wide spread pharmaceutical activity. ${ }^{1}$

The World Drug Index contains well over 100 drugs including a thiazole unit as a core scaffold, a capping fragment or a component in a hybrid system. Furthermore, the thiazole derivatives have been reported to have broad spectrum biological activities as anticancer ${ }^{2}$ antifungal, antibacterial, antidiabetic, anticonvulsant, anti-inflammatory, anti HIV, antioxidant, Anti-Alzheimer and antihypertensive agents. ${ }^{3-5}$ The major structural feature doing thiazole ring so popular is the nitrogen, which forms a strong complex with its target participating in donoracceptor type interactions with the substrate. Thiazoles with derivatives of pyridine are important part of heterocyclic chemistry constituting the structure of Vitamin B1 (thiamine) which is of biological and pharmaceutical interest. Thiazole derivatives offer peptidomimetic features and improve compound's solubility and rigidity by maintaining hydrogen bond acceptors. Thiazole-based fragments are more flexible and bond more effectively with hydrogen. The structures of some representative examples of widely used antibiotics like Penicillin, Ampicillin, Myxothiazoles, Melithiazoles, Cystothiazoles, Bleomycins and Abafungin ${ }^{6}$ are given below:

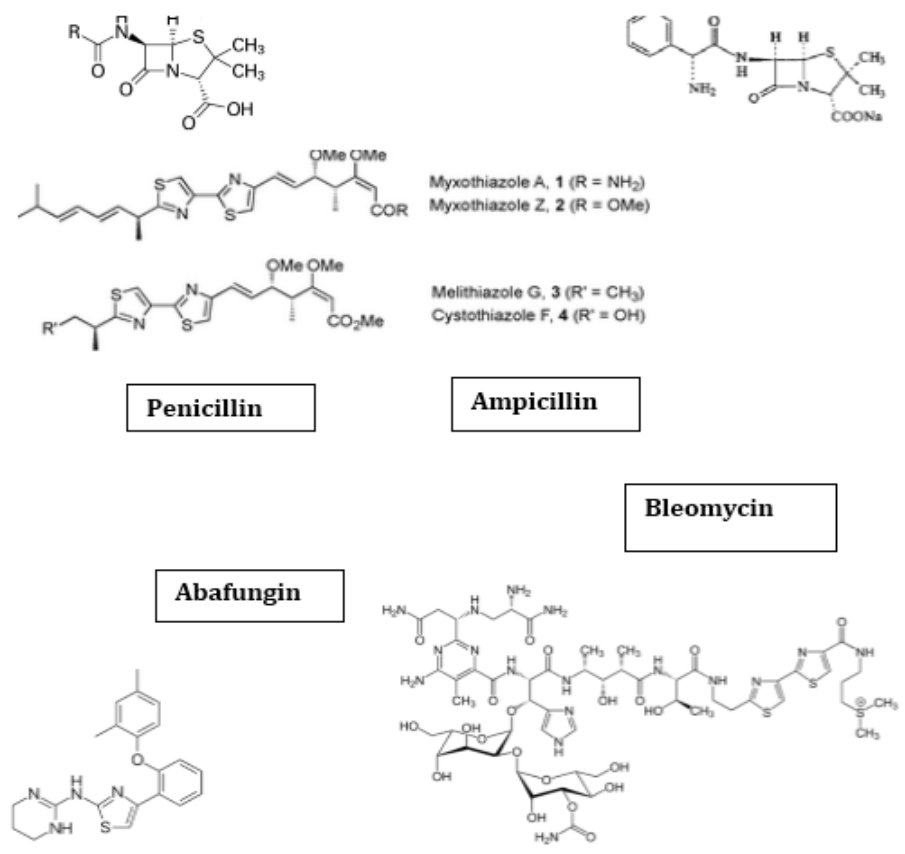

\section{Hantzsch Synthesis of Thiazole Derivatives}

In 1888, Hantzsch and Traumann Synthesis derived a unique method of synthesis of 2-aminothiazoles by cyclization of thiourea or thioamides with $\alpha$-halo ketones and iodine. ${ }^{7}$ The advantage is the high yield of

This is an open access article distributed under the terms of the Creative Commons Attribution-NonCommercial-ShareAlike 4.0 License, which allows others to remix, tweak, and build upon the work non-commercially, as long as the author is credited and the new creations are licensed under the identical terms. 
aminothiazoles. It can also be synthesized by various methods such as Gabriel Synthesis where a acyl amino derivative are reacted with Phosphorous pentasulphide and Cook-Heilbron thiazole synthesis which is the synthesis of 5 -aminothiazoles by reacting $\alpha$-aminonitriles or aminocynoacetates with dithioacids, carbon disulphide, carbon oxysulfide, or isothiocynates at room temperature and under mild conditions. The Hantzsch thiazole synthesis was extended to a halocyclic ketone, acyclic ketone, polycyclic ketones and aryl ketones with substituted thiourea and iodine. Variation of substituents at the $\mathrm{R}^{1}, \mathrm{R}^{2}$ and $\mathrm{R}^{3}$ of the thiazole is introduced by selecting different combinations of starting reagents.

\section{Mechanism of Hantzsch Thiazole Synthesis ${ }^{8}$}
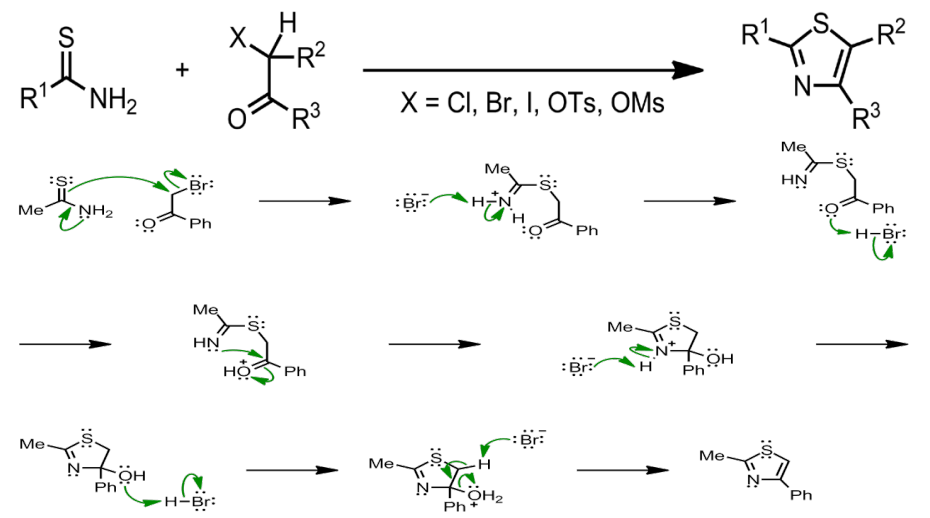

\section{Cancer}

Cancer is the most fatal, widespread disease with high rate of mortality in the world today. The high mortality rate of cancer results from uncontrolled multiplication of subtly modified normal human cells. Cancer can be treated by Surgery or Chemotherapy or Radiation therapy or Hormonal therapy or Immunotherapy or Targeted therapy or the combination of one or more above mentioned therapies. The two different types of chemotherapeutic agents are cytostatic and cytotoxic agents. The cytostatic agents have been beneficial in fighting tumors with their ability to arrest the cell growth and multiplication (apoptosis) but do not result in the cell death directly. Eg: Nitric oxide for Breast Cancer, Long chain polyunsaturated fatty acids for malignant epithelium. The Cytotoxic agents destroy or kill the rapidly growing cancer cells, they are classified $^{9}$ as 1) Alkylating agents: eg Cisplatin, 2) Antimetabolites: Vincristine, 3) Antibiotics: Bleomycins, 4) Miscellaneous: Hydroxy Urea. Chemotherapy is the only effective therapy for some type of cancers and so there is a raised expectation to develop more potent and selective agents.

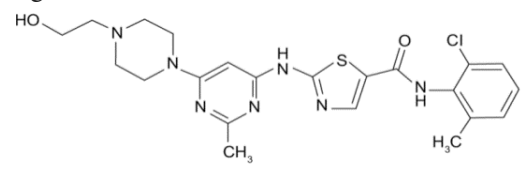

Dasatinib $^{10}$

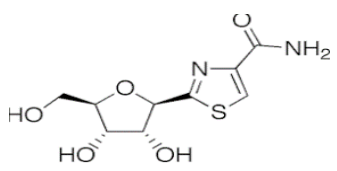

Tiazofurin $^{11}$
The active chemotherapeutic agents Dasatinib and Tiazofurin have 1,3 thiazole ring, which prompted us to synthesize new series of 1,3 thiazole derivatives and evaluate their anticancerous activity.

\section{MATERIALS AND METHODS}

\section{Synthetic Method}

Melting points are uncorrected; the UV spectra were recorded on Shimadzu 1601 spectrometer, IR (KBr) were recorded on Perkin-Elmer
FT-IR 1600 spectrometer, ${ }^{1} \mathrm{H}$ NMR spectra were recorded on Brucker AMX 400 using the solvent (CDCl 37.26 ppm and 77.0 ppm, DMSO-d6 $2.49 \mathrm{ppm}$ and $39.7 \mathrm{ppm}$ ) and TMS used as an internal standard. Lowresolution MS data were obtained using ESI and high-resolution spectra were recorded on QSTARXL hybrid MS/MS system Elemental analyses were within $\pm 0.4 \%$ of their calculated values. For Molecular Docking, the ligand structures are built by using builder in Molinspiration Cheminformatics and converted to 3D with Corina 3D. The synthesized molecules (ligands) were docked into the active site using Molecular docking software PATCH Dock with default parameters. The precise location of the binding site and the potentiality of the ligand to bind to the active site were determined using an automated docking software, molegro virtual docker 2008, version 3.2.1 (MolegroApS, Aarhus, Denmark, http://molegro.com).

Procedure: Step 1 Hantzsch Reaction: A mixture consisting of 0.1 mole of ketone, 0.2 mole of thiourea and 0.1 mole of Iodine were heated overnight on the steam bath. This crude reaction mixture was cooled and extracted with ether to remove unreacted ketone and iodine. This residue was then dissolved in boiling water and filtered to remove sulphur. Then the solution was cooled somewhat and made basic with ammonium hydroxide. The 2-amino, 4-substituted phenyl thiazole, which separated, was recrystallized from water and alcohol. The four different parent compounds synthesized from following four different ketones a) p-methoxy acetophenone b) acetophenone c) p-chloro acetophenone d) p-hydroxy acetophenone.

Step 2: Schiff's Reaction: Further the above synthesized compounds was subjected to schiff's reaction with substituted Aryl aldehydes and corresponding 2-amino substituted derivatives were synthesized.

A mixture of Substituted aldehydes $(0.004 \mathrm{~mol})$ and 2- amino substituted thiazole (products from step 1$)(0.004 \mathrm{~mol})$ in ethanol $(10 \mathrm{ml})$ were added in microwave. The contents were subjected to microwave irradiation at $200 \mathrm{~W}$ for about $30 \mathrm{sec}-2 \mathrm{~min}$. After the completion of the reaction, solid product was obtained in reaction mixture which was filtered and recrystallized with methanol. The scheme of the reaction is shown below and scheme of synthesis is shown in Table 1. The Molecular mass, IR and NMR spectral data of the synthesized compounds is recorded in Table 2. Scheme of Reaction.
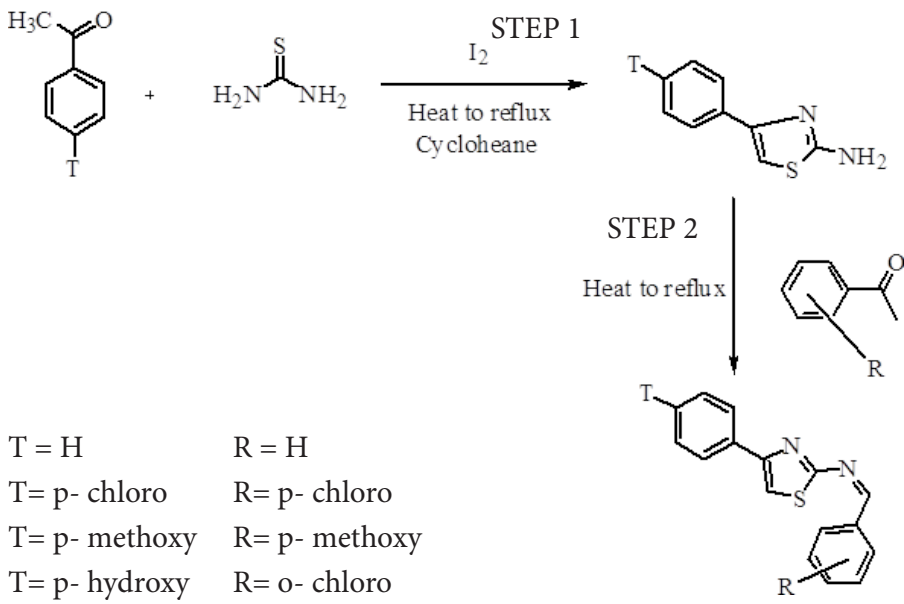

$$
\begin{array}{ll}
\mathrm{T}=\mathrm{H} & \mathrm{R}=\mathrm{H} \\
\mathrm{T}=\mathrm{p} \text { - chloro } & \mathrm{R} \text { = } \text { - } \text { chloro } \\
\mathrm{T} \text { = p- methoxy } & \mathrm{R} \text { = } \text { - } \text { - methoxy } \\
\mathrm{T}=\text { p- hydroxy } & \mathrm{R} \text { = } \text { - } \text { - chloro }
\end{array}
$$

Path 1 para-methoxyacetophenone + o chloro Benzaldehyde

$$
\begin{aligned}
& + \text { Benzaldehyde } \\
& + \text { p methoxy Benzaldehyde (Anisaldehyde) } \\
& + \text { p chloro Benzaldehyde } \\
& + \text { o chloro Benzaldehyde } \\
& + \text { Benzaldehyde } \\
& + \text { p methoxy Benzaldehyde (Anisaldehyde) }
\end{aligned}
$$$$
\text { Path } 2 \text { acetophenone } \quad+\text { o chloro Benzaldehyde }
$$ 
+ p chloro Benzaldehyde

Path 3 para-hydroxyacetophenone +o chloro Benzaldehyde + Benzaldehyde

+ p methoxy Benzaldehyde (Anisaldehyde)

+ p chloro Benzaldehyde

Path 4 para-chloroacetophenone +o chloro Benzaldehyde

+ Benzaldehyde

$+\mathrm{p}$ methoxy Benzaldehyde (Anisaldehyde)

$+\mathrm{p}$ chloro Benzaldehyde

\section{Anti-cancerous in vitro activity- Method}

MCF cell lines were procured from National Centre for Cell Sciences (NCCS), Pune, India. Stock cells were cultured in their respective media viz., MEM/DMEM-HG/Ham's F-12 supplemented with 10\% inactivated Fetal Bovine Serum (FBS), penicillin (100 IU/ml), streptomycin (100 $\mu \mathrm{g} / \mathrm{ml})$ and amphotericin B $(5 \mu \mathrm{g} / \mathrm{ml})$ in an humidified atmosphere of $5 \% \mathrm{CO}_{2}$ at $37^{\circ} \mathrm{C}$ until confluent. The cells were dissociated with TPVG solution ( $0.2 \%$ trypsin, $0.02 \%$ EDTA, $0.05 \%$ glucose in PBS). The stock cultures were grown in $25 \mathrm{~cm}^{2}$ culture flasks and all experiments were carried out in 96 well microtitre plates (Tarsons India Pvt. Ltd., Kolkata, India).

In all the cell lines, the monolayer cell culture was trypsinized and the cell count was adjusted to 100,000 cells/ml using respective media viz., MEM/DMEM-HG/Ham's F-12 containing $10 \%$ BS. To each well of the 96 well microtitre plate, $0.1 \mathrm{ml}$ of the diluted cell suspension was added. After $24 \mathrm{~h}$, when a partial monolayer was formed, the supernatant was flicked off, monolayer washed once with medium and $100 \mu \mathrm{l}$ of different test concentrations of test substances were added on to the partial monolayer in microtitre plates. The plates were then incubated at $37^{\circ} \mathrm{C}$ for $72 \mathrm{~h}$ in $5 \% \mathrm{CO}_{2}$ atmosphere and microscopic examination was carried out and observations were noted every $24 \mathrm{~h}$ interval.

\section{MTT assay}

After $72 \mathrm{~h}$ incubation, the drug solutions in the wells were discarded and $50 \mu \mathrm{l}$ of MTT in PBS was added to each well. The plates were gently shaken and incubated for $3 \mathrm{~h}$ at $37^{\circ} \mathrm{C}$ in $5 \% \mathrm{CO}_{2}$ atmosphere. The supernatant was removed and $100 \mu \mathrm{l}$ of propanol was added and the plates were gently shaken to solubilize the formed formazan. The absorbance was measured using a microplate reader at a wavelength of $540 \mathrm{~nm}$. The mean values of all the compounds is given in Table 3 . The percentage growth inhibition was calculated mathematically and concentration of test substances needed to inhibit cell growth by $50 \%$ (CTC50) values was generated from the dose-response curves for each cell line (Table 4).

\section{Molecular Docking Method}

Molecular docking studies were carried out by docking the synthesized compounds on RAS p21. RAS p 21 is a protein which inactivates RAS from its active GTP- bound form to inactive GDPbound form thereby allowing control of cellular proliferation and differentiation. A frequent oncogenic mutation of H-ras, N-ras, or K-ras genes is seen in different types of cancerous tumours. The members of the Ras GTPase family are crucial players in many signaling networks in the pathways linked to the functional controls of cell cycle progression, growth, migration, cytoskeletal changes, apoptosis and senescence. The refined crystal structure of the triphosphate conformation of $\mathrm{H}$-Ras p21 (5P21) was retrieved from Protein Data Bank and the protein structure was corrected by using Protonate 3D and energy minimization was done. The ligands structures are built using MOLINSPIRATION and CORINA 3D software. The active site of protein was predicted by using site finder with default settings, dummies were assigned. The constructed structures of the ligands were docked into the active site using Molecular docking software PATCH Dock with default parameters. Molecular docking of the molecules revealed the atomic contact energy (ACE) and the amino acid binding residues that are as depicted in Table 5. The precise location of the binding site and the potentiality of the ligand to bind to the active site were determined using automated docking software, that is based on guided differential evolution and a force filed based screening function. With the help of clustering methods, the possible binding conformations and orientations were determined. The enzyme was visualized using the sequence option. The binding site was calculated within a spacing range so that the binding site was well into the grid and interactions were analysed using detailed energy estimates. The PATCH Dock software was utilized to identify Atomic contact energy, hydrogen bonds and hydrophobic interactions between residues at the active site and the ligand. The corresponding results were tabulated in the Table 5. As per the docking results, the compounds that showed maximum affinity to the receptor and shown the best anticancerous activity in the ascending order are as follows: $\mathrm{S} 3 \mathrm{P} 2 \mathrm{c}$, S3P2d, S3P4d, S3P1c, S3P3a and S3P2c.The images of the docking of the compounds with the Biomarker Ras p21 is depicted in Figure 1.

\section{RESULTS}

The IUPAC name, molecular mass, NMR and IR data of the synthesized compounds is given in the Table 2. When the IR spectras of the synthesized compounds were analyzed, it was seen that a distinct peak at $2575-2295 \mathrm{~cm}^{-1}$ which represents the formation of thiazole ring and completion of step 1 of the synthesis. A peak at $2278-2279 \mathrm{~cm}^{-1}$ was seen in all the compounds distinct from that of the parent compound. This peak is due to the imine group $-\mathrm{C}=\mathrm{N}$ - which represents the completion of step 2 synthesis. When the NMR spectras of the synthesized were analyzed, it was observed generally that the aromatic hydrogens ortho to the electron withdrawing substitutes like chloro showed desheilding effect and are shifted to downfield.

\section{Mean values of percentage inhibitions and graphs of percentage inhibition Vs concentrations}

The percentage inhibition of the cellular growth at different concentrations is tabulated and the graph is also plotted. The $\mathrm{CTC}_{50}$ which is the cytotoxic concentration at which $50 \%$ of the cancer cells die after exposure to the synthesized compounds is calculated. Lower the $\mathrm{CTC}_{50}$, better the anti -cancerous activity. Based on this it was decided that S3P2c, S3P2d, S3P1c, S3P4d and S3P3a were the most active anti cancerous compounds.

\section{Results of Docking}

A three dimensional structures of the synthesized molecules was developed and docked with the RAS p21.

Human Protein receptor (from PDB). During the docking procedure, only the best fit active site pocket with respect to the ligands is selected. Then respective Atomic Contact Energy and active protein site (amino acid residues) and the interactive hydrogen bonds is tabulated in Table 5. The best docked conformation of the receptor and the ligand is depicted in Figure 1. Lower the atomic contact energy, better the ligand binding and is eligible to be a promising candidate for anticancerous activity. 


\section{Table 1: Scheme of Synthesis.}

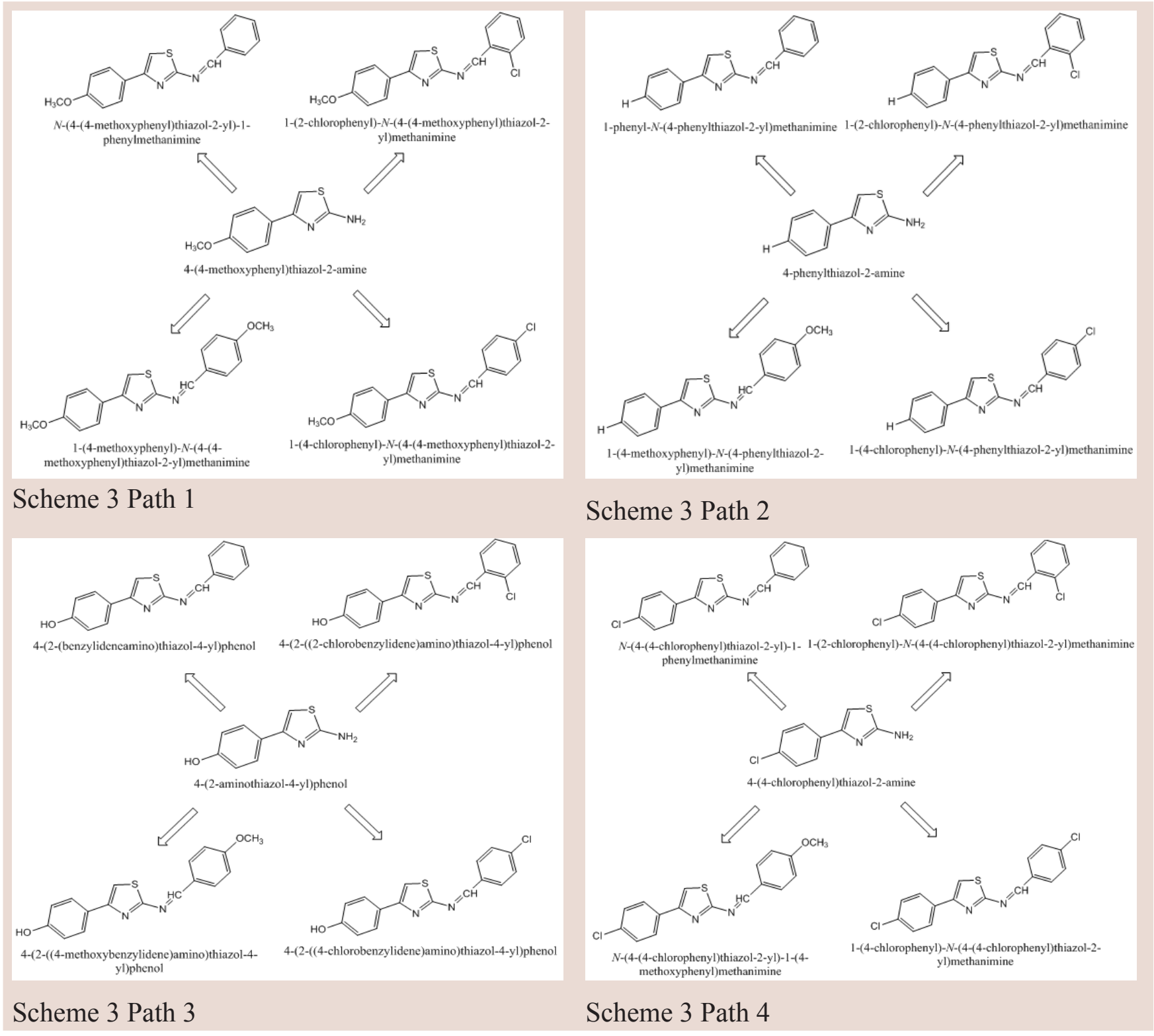

Table 2: Spectral Data of the synthesized compounds.

Chemical / IUPAC Name
S3P1a $\begin{gathered}\begin{array}{c}\text { Infrared Spectroscopy Values } \\ \text { Benzylidene-[4-(4-methoxy-phenyl)-thiazol-2-yl]-amine }\end{array} \\ \text { Molecular Mass } 295.18 \\ \mathrm{HNMR} \text { data (ppm) }: 2991.26 \mathrm{~cm}^{-1}\end{gathered}$




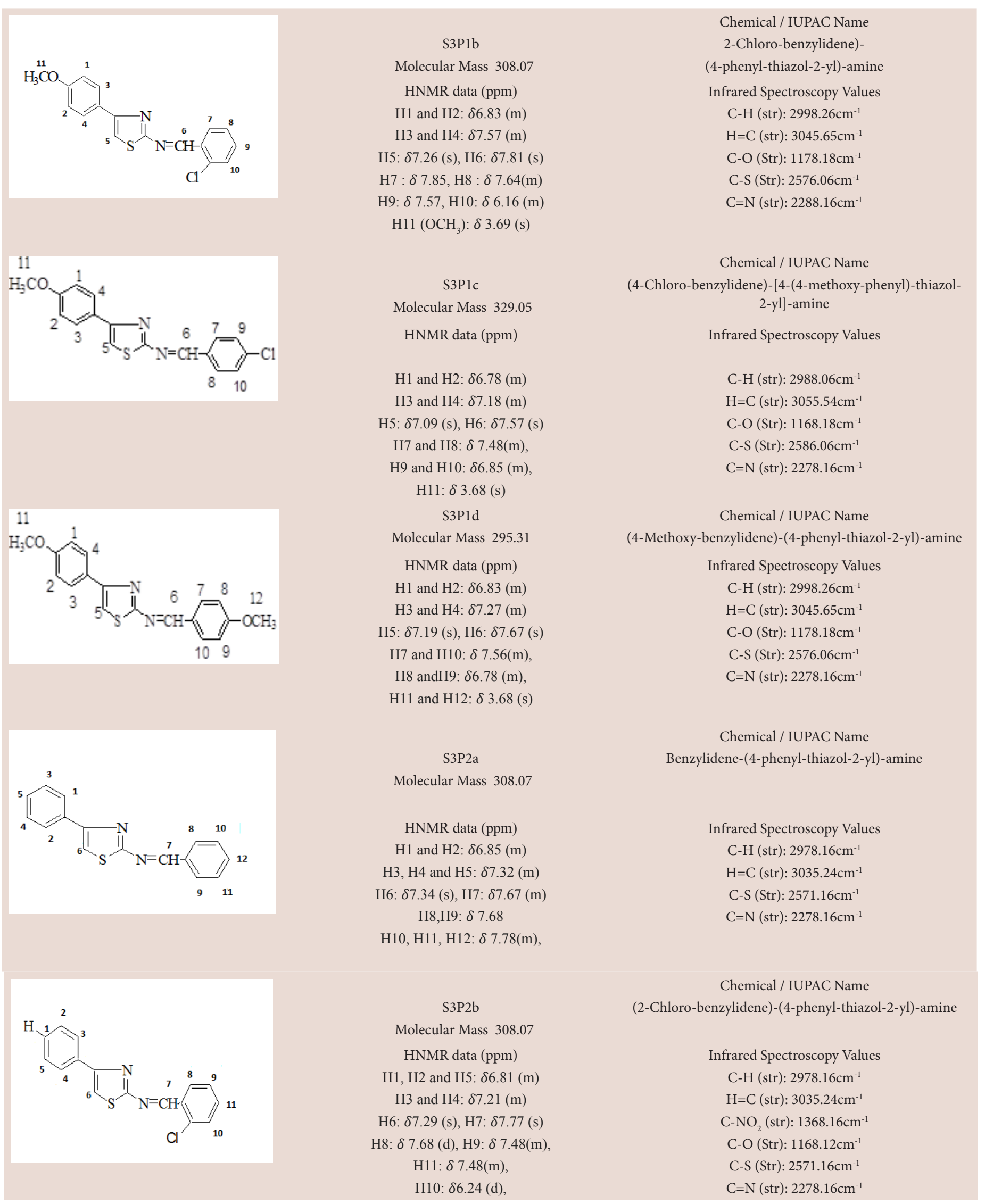




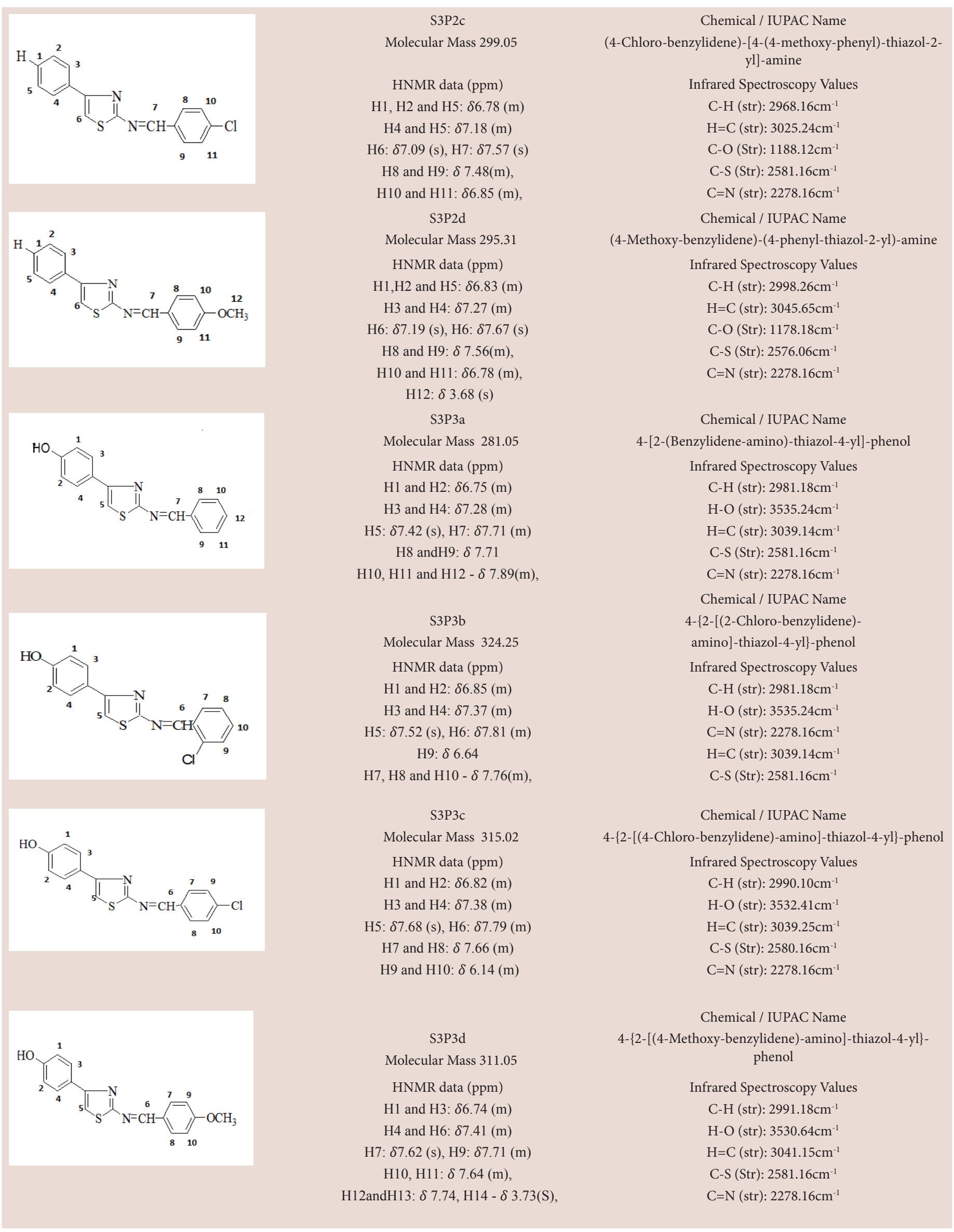




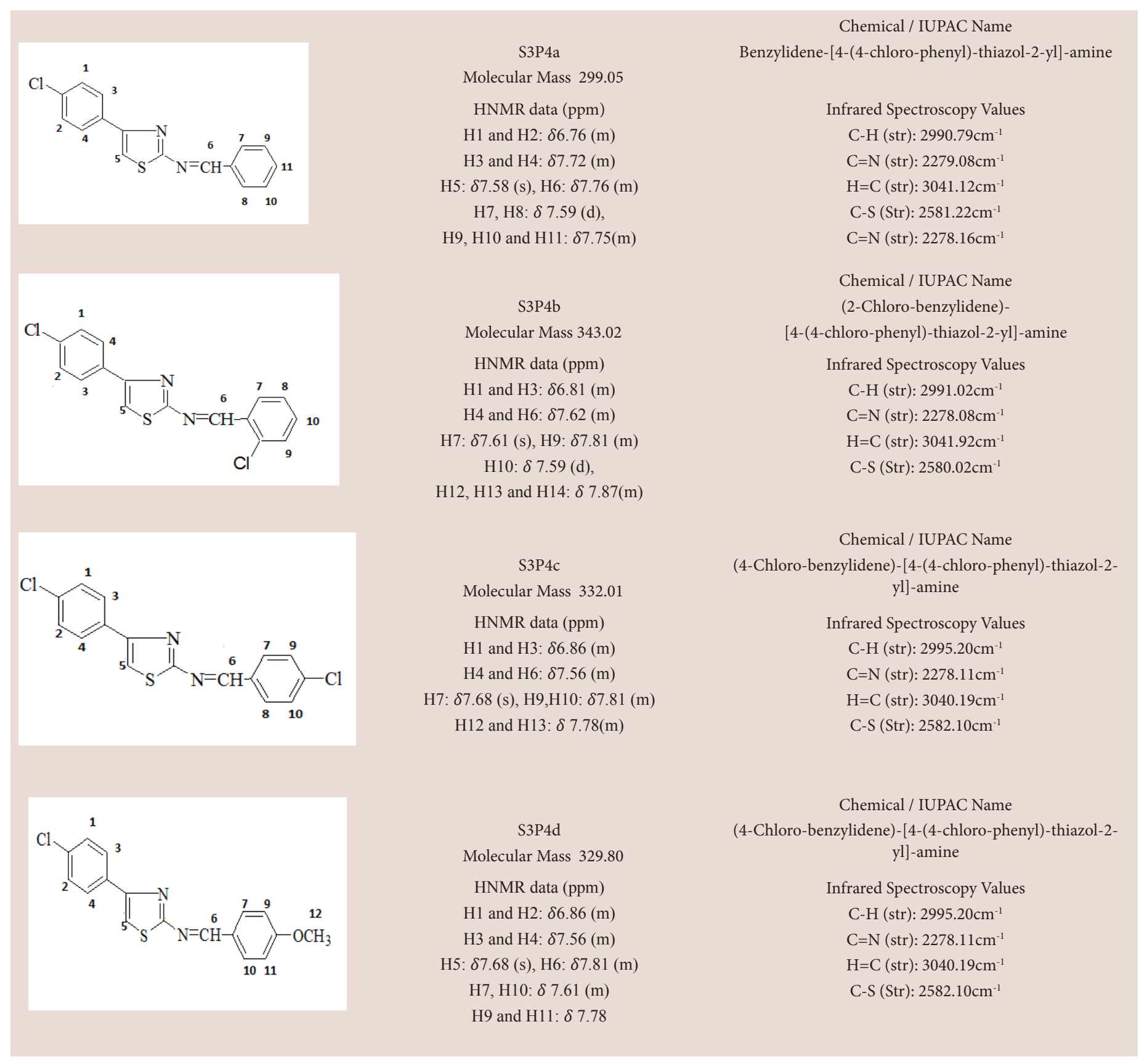

Table 3(a): Cytotoxic activity of S3P1a to S3P1 d and S3P2a to S3P2d.

\begin{tabular}{ccccccccc}
\hline con in $\mu \mathrm{M}$ & S3P1a & S3P1b & S3P1c & S3P1d & S3P2a & S3P2b & S3P2c & S3P2d \\
\hline 5 & $13.63 \pm 0.14$ & $7.7 \pm 0.36$ & $29.94 \pm 0.27$ & $15.59 \pm 0.14$ & $14.53 \pm 0.33$ & $18.97 \pm 0.50$ & $36.41 \pm 0.25$ & $34.9 \pm 0.25$ \\
10 & $14.53 \pm 0.38$ & $9.6 \pm 0.26$ & $40.93 \pm 0.22$ & $16.22 \pm 0.38$ & $16.29 \pm 0.24$ & $33.09 \pm 0.41$ & $46.38 \pm 0.20$ & $45.11 \pm 0.21$ \\
20 & $19.87 \pm 0.32$ & $16.5 \pm 0.40$ & $55.45 \pm 0.99$ & $20.96 \pm 0.67$ & $22.68 \pm 0.37$ & $42.56 \pm 0.38$ & $59.56 \pm 0.90$ & $58.6 \pm 0.92$ \\
30 & $26.45 \pm 0.5$ & $22.03 \pm 1.01$ & $58.3 \pm 0.37$ & $28.65 \pm 0.10$ & $27.8 \pm 0.93$ & $51.55 \pm 0.14$ & $62.66 \pm 0.12$ & $61.25 \pm 0.34$ \\
40 & $38.22 \pm 0.32$ & $38.63 \pm 0.21$ & $67.76 \pm 0.29$ & $46.96 \pm 0.27$ & $43.17 \pm 0.19$ & $61.02 \pm 0.11$ & $73.3 \pm 0.27$ & $70.05 \pm 0.5$ \\
50 & $51.19 \pm 1.02$ & $49.9 \pm 0.1$ & $69.97 \pm 0.35$ & $61.5 \pm 0.43$ & $53.61 \pm 0.09$ & $69.47 \pm 0.19$ & $84.15 \pm 0.28$ & $76.69 \pm 0.28$ \\
100 & $65.76 \pm 0.05$ & $62.2 \pm 0.1$ & $75.76 \pm 0.31$ & $67.57 \pm 0.05$ & $65 \pm 0.09$ & $72.48 \pm 0.31$ & $93.92 \pm 0.21$ & $82.46 \pm 0.16$ \\
\hline
\end{tabular}


Table 3(b): Cytotoxic activity of S3P3a to S3P3d and S3P4a to S3P4d.

\begin{tabular}{|c|c|c|c|c|c|c|c|c|}
\hline con in $\mu \mathrm{M}$ & S3P3a & S3P3b & S3P3C & S3P3d & S3P4a & S3P4b & S3P4c & S3P4d \\
\hline 5 & $25.18 \pm 0.29$ & $12.09 \pm 0.34$ & $17.73 \pm 0.09$ & $17.07 \pm 0.28$ & $10.38 \pm 0.35$ & $16.47 \pm 0.33$ & $21.2 \pm 0.6$ & $30.53 \pm 0.3$ \\
\hline 10 & $36.92 \pm 0.24$ & $13.9 \pm 0.25$ & $21.87 \pm 0.74$ & $18.03 \pm 0.38$ & $12.23 \pm 0.26$ & $18.19 \pm 0.24$ & $39.12 \pm 0.64$ & $41.42 \pm 0.2$ \\
\hline 20 & $52.42 \pm 1.06$ & $20.47 \pm 0.38$ & $28.95 \pm 0.74$ & $25.52 \pm 0.16$ & $18.93 \pm 0.39$ & $24.43 \pm 0.36$ & $45.21 \pm 0.19$ & $55.82 \pm 1.0$ \\
\hline 30 & $55.47 \pm 0.39$ & $25.74 \pm 0.96$ & $46.9 \pm 0.23$ & $35.26 \pm 0.29$ & $24.3 \pm 0.98$ & $29.44 \pm 0.51$ & $53.45 \pm 0.41$ & $60.89 \pm 0.1$ \\
\hline 40 & $65.58 \pm 0.84$ & $41.55 \pm 0.20$ & $56.01 \pm 0.27$ & $52.51 \pm 0.14$ & $40.42 \pm 0.20$ & $44.46 \pm 0.19$ & $62.77 \pm 0.78$ & $68.03 \pm 0.3$ \\
\hline 50 & $73.21 \pm 0.33$ & $52.28 \pm 0.1$ & $63.1 \pm 0.23$ & $63.28 \pm 0.38$ & $51.35 \pm 0.1$ & $54.66 \pm 0.09$ & $67.75 \pm 0.28$ & $71.76 \pm 0.3$ \\
\hline 100 & $75.32 \pm 0.19$ & $64 \pm 0.1$ & $68.2 \pm 0.05$ & $66.9 \pm 0.23$ & $63.3 \pm 0.1$ & $65.79 \pm 0.09$ & $70.55 \pm 0.28$ & $77.08 \pm 0.2$ \\
\hline
\end{tabular}

Table 4: The CTC $_{50}$ in $\mu \mathrm{M}$ values of all synthesized compounds.

\begin{tabular}{rlllllll}
\hline S3P1a & 65.13416537 & S3P2a & 62.85939968 & S3P3a & 34.96904025 & S3P4a & 66.7788162 \\
S3P1b & 69.13867488 & S3P2b & 41.60060976 & S3P3b & 65.20689655 & S3P4b & 61.06687898 \\
S3P1c & 32.26229508 & S3P2c & 22.75324675 & S3P3c & 50.44207317 & S3P4c & 40.18181818 \\
S3P1d & 58.11487482 & S3P2d & 26.34556575 & S3P3d & 54.79638009 & S3P4d & 30.77170418 \\
\hline
\end{tabular}

Table 5: ACE values, details of hydrogen bonds and amino acid residues on the docked domain.

\begin{tabular}{|c|c|c|c|c|c|c|}
\hline SI no & $\begin{array}{l}\text { Name of } \\
\text { Biomarkers }\end{array}$ & $\begin{array}{l}\text { Compound } \\
\text { Code }\end{array}$ & & $\begin{array}{l}\text { Details of } \\
\text { Hydrogen Bonds }\end{array}$ & $\begin{array}{l}\text { Atomic } \\
\text { Contact } \\
\text { Energy }\end{array}$ & Amino acid residues on the docked domains \\
\hline 1 & & S3P1a & 06 & $3.96,5.08,4.62,4.09,2.5,1.62$ & -121.86 & $\begin{array}{l}\text { Tyr 32, Pro } 34 \text {, Gly 60, Gln 61, Arg 68, Asp 92, } \\
\text { Gln 95, Tyr } 96\end{array}$ \\
\hline 2 & & S3P1b & 07 & $0.45,-2.5,1.71,2.27,2.45,1.04,1.22$ & -103.74 & $\begin{array}{l}\text { Gly 60, Glu 62, Arg 68, } \\
\text { Asp 92, Gln 95, Glu } 98\end{array}$ \\
\hline 3 & & S3P1c & 05 & $-0.74,-2.5,-2.5,0.56,13.02$ & -173.07 & Ile 36, Pro 34, Tyr 32, Glu 63, Gln 61, Gly 13 \\
\hline 4 & & S3P1d & 04 & $-2.5,7.9,1.12,-2.5$ & -140.88 & $\begin{array}{l}\text { Lys } 5 \text {, Glu } 37 \text {, Asp } 54 \text {, Leu } 56 \text {, Met } 67 \text {, Gln } 70 \text {, } \\
\text { Tyr } 70 \text {, Thr } 74\end{array}$ \\
\hline 5 & & $\mathrm{~S} 3 \mathrm{P} 2 \mathrm{a}$ & 05 & $-1.46,-1.01,3.02,0.84,-0.904$ & -121.60 & $\begin{array}{l}\text { Gly 60, Gln 61, Arg 68, Asp 92, Gln 95, Tys 96, } \\
\text { Gln } 99\end{array}$ \\
\hline 6 & & $\mathrm{~S} 3 \mathrm{P} 2 \mathrm{~b}$ & 01 & -2.5 & -160.47 & Tyr 32, Pro 34, Gln 61, Glu63 \\
\hline 7 & & $\mathrm{~S} 3 \mathrm{P} 2 \mathrm{c}$ & 03 & $-1.99,-2.2,-2.5$ & -249.05 & $\begin{array}{l}\text { Gly } 12 \text {, Gly } 13 \text {, Glu } 31 \text {, Tyr } 32 \\
\text { Asp 33, Pro 34, Gln } 61\end{array}$ \\
\hline 8 & & S3P2d & 02 & $-2.5,0.51$ & -196.31 & $\begin{array}{l}\text { Gly 12, Tyr } 32 \text { Asp 33, Pro } 34 \\
\text { Gln } 61\end{array}$ \\
\hline 9 & & S3P3a & 03 & $1.24,-1.15,-2.5$ & -162.71 & Tyr 32, Pro 34 Gln 61, Glu 63 \\
\hline 10 & & S3P3b & 10 & $\begin{array}{l}-0.02,-0.54,-0.86,5.59,9.65,-0.14,-2.5 \\
-2.5,-1.46\end{array}$ & -109.00 & $\begin{array}{l}\text { Gly 60, Gln 61, Glu 62, Arg 68, } \\
\text { Gln 95, Tyr } 96\end{array}$ \\
\hline 11 & & S3P3c & 05 & $-2.5,5.25,4.98,1.86,-0.57$ & -158.97 & Gln 131, Arg 135, Tyr 141 \\
\hline 12 & & S3P3d & 05 & $-1.13,-2.5,-1.84,10.72,-2.22$ & -137.16 & $\begin{array}{l}\text { Lys } 5 \text {, Glu } 37 \text {, Asp } 54 \text {, Leu } 54 \text {, Tyr } 64 \text {, Met } 67 \text {, } \\
\text { Gln } 70 \text {, Tyr } 71 \text {, Thr } 74\end{array}$ \\
\hline 13 & RAS p 21 & S3P4a & 01 & -1.34 & -105.79 & $\begin{array}{l}\text { Lys } 5 \text {, Glu } 37 \text {, Asp } 54 \text {, } \\
\text { Leu } 56 \text {, Tyr } 64 \text {, Gln } 70\end{array}$ \\
\hline 14 & & $\mathrm{~S} 3 \mathrm{P} 4 \mathrm{~b}$ & 06 & $-0.35,-2.12,-0.16,-1.99,-4.15,-2.5$ & -132.21 & $\begin{array}{l}\text { Ala 11, Gly 60, Gln 61, Glu 62, } \\
\text { Arg 68, Asp 92, Gln 95, Tyr } 96 \text { Gln } 99\end{array}$ \\
\hline 15 & & $\mathrm{~S} 3 \mathrm{P} 4 \mathrm{c}$ & 06 & $-0.79,-2.5,1.09,-1.19-2.5,-1.82$ & -158.74 & $\begin{array}{l}\text { Gln 70, Thr } 74 \text { Lys 5, Tyr 71, Glu } 37 \text { Tyr 64, Met } \\
67\end{array}$ \\
\hline 16 & & S3P4d & 02 & $-2.5,-2.5$ & -192.62 & $\begin{array}{l}\text { Gly } 13 \text {, Tyr } 32 \text { Pro } 34 \text {, ile } 36 \\
\text { Gln 61, Glu } 63\end{array}$ \\
\hline
\end{tabular}




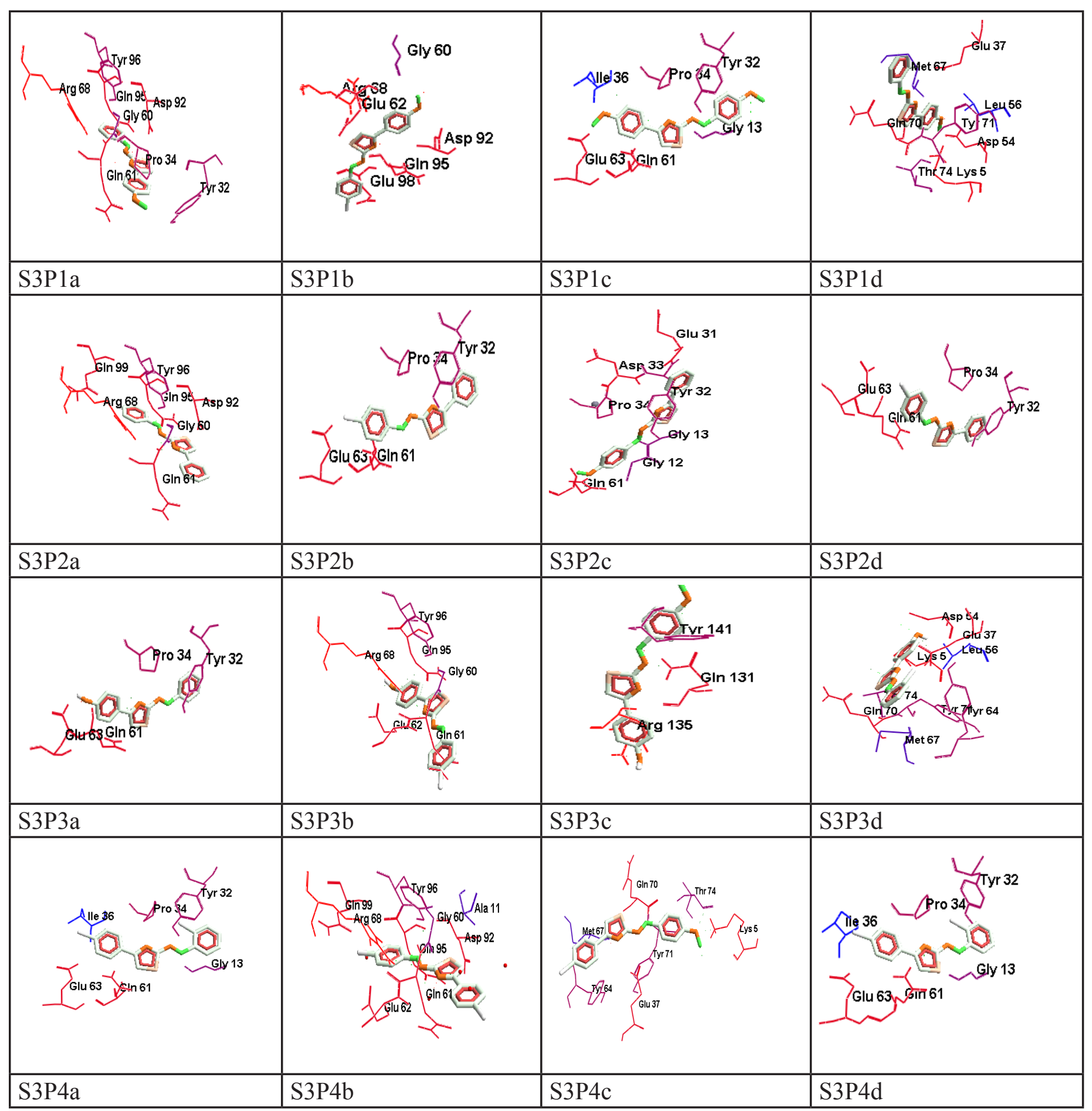

Figure 1: Docking pictures of the compounds with the Ras p21 Biomarker.

\section{DISCUSSION}

Amongst the wide range of small-ring heterocycles explored, rings including nitrogen and sulfur have been under investigation for a long time on account of their synthetic diversity and therapeutic relevance. The thiazoles have been identified as the most privileged candidates in drug discovery because of their diverse pharmaceutical activity. The thiazole derivatives are known to have potent anti-cancerous activity. As per the chemistry of the 1,3 thiazoles is biologically most active which is proved by Tiazofurin, Thiazole Netropsin and Bleomycin. Epithalones is a recent class of natural products which have been reported to exhibit extraordinarily potent cytotoxicity in a broad range of human cancer cell lines, The newer anti-neoplastic antibiotics such as Siomycine A, Thiostreptone, Nosiheptide, Sporangiomycin and Thiopeptine are also 1,3 thiazoles. 2, 4-disubstituted 1,3 thiazole is proved to be potent antineoplastic agents in the Structure Activity Related studies and they show desired pharmacological actions because of their relative stability, enhanced lipid solubility and also hydrophilicity. They are proved to have better ADME properties. 2 amino derivatives of thiazole is proved to be a potent anticancerous drug. ${ }^{12}$ In the recent similar studies it is 
seen that 2,4,5 tri substituted thiazole is proven to have anti-cancerous activity. ${ }^{13}$ There are a variety of mechanisms for the antitumor action of thiazole and fused thiazole derivatives, acting on cancer biotargets, such as tumor necrosis factor TNF- $\alpha$ inosine monophosphate dehydrogenase (IMPDH) and apoptosis inducers.

Based on the above studies, sixteen derivatives of 2, 4-disubstituted 1,3 thiazole were synthesized and were screened for in vitro anti-cancerous activity on breast cell line and found that all the derivatives showed moderate to good inhibition of cell proliferation following MTT Assay. This assay is based on the assumption that dead cells or their products do not reduce tetrazolium. The assay depends both on the number of cells present and on the mitochondrial activity per cell. The principle involved is the cleavage of tetrazolium yellow coloured salt 3-(4, 5 dimethyl thiazole-2-yl)-2, 5-diphenyl tetrazolium bromide (MTT) into a blue coloured product (formazan) by mitochondrial enzyme succinate dehydrogenase. Hence it is a colorimetric assay. The number of cells was found to be proportional to the extent of formazan production by the cells used. Therefore this assay is used for assessing cell viability.

The synthesized compounds were docked with Ras $\mathrm{p} 21$ protein receptor. In the docking studies the optimum Atomic Contact Energy of ligandreceptor binding is usually between -100 to -250 scores. If the ACE score is less than -100 , then it is not sufficiently bound to exhibit the expected pharmacological activity and if it is higher than -250, then the binding is so strong that the dissociation of the ligand from the receptor becomes difficult and leads to the toxicity.

\section{CONCLUSION}

A series of sixteen compounds were synthesized by following the standardized and established procedures. Molecular docking studies were also carried out for all the new compounds with Ras p21 which is a protein involved in control of proliferation of cancerous cells. All the compounds were screened for in-vivo anti cancerous activity on the breast cell lines and most of the synthesized compounds have shown moderate to good anti cancerous activity. Amongst all the 16 compounds, S3P1c, S3P2c, S3P2d, S3P3a and S3P4d have shown the best activity. When analysed, the presence of methoxy group and chloro substitutions have influenzed the increase in the activity.

\section{ACKNOWLEDGEMENT}

I would like to express my sincere gratitude to my Guide and my University, Dayananda Sagar University for their continuous support.

\section{CONFLICT OF INTEREST}

The authors declare no conflict of interest.

\section{ABBREVIATIONS}

TLC: Thin Layer Chromatography; MP: Melting Point; R Values: Gas constant; IR: Infra-red; UV: Ultraviolet; NMR: Nuclear Magnetic Resonance; MS: Mass Spectroscopic; CHN: Carbon hydrogen and nitrogen; FTIR: Fourier-transform infrared spectroscopy; $\mathrm{KBr}$ : Potassium bromide; H1NMR: Hydrogen-1 NMR; CdCl: Cadmium Chloride; DMSO: Dimethyl Sulfoxide; DB: Protein DATA Bank; ACE: Atomic Contact Energy, viz- that is to say.

\section{REFERENCES}

1. Katritzky AR. Handbook of Heterocyclic Chemistry. Newyork: Pergamon Press. 1985.

2. Sarangi PKN, Sahoo J, Paidesetty SK, Mohanta GP. Thiazoles as Potent Anticancer Agents: A Review. Indian Drugs. 2016;53(11):5-11.

3. Gupta V, Kant V. A review of biological activity of imidazole and thiazole moieties and their derivatives. Sci Int. 2013;1(7):253-60

4. Demirci S. Synthesis of Thiazole Derivatives as Antimicrobial Agents by Green Chemistry Techniques. J Turkish Chem Soc Sect Chem. 2018;5(2):393-414.

5. Kaur H, Goyal A. A Review on Thiazole as Anticancer Agents. Int J Pharm Drug. 2018;6(5):509-22.

6. Althagafi I, El-Metwaly N, Farghaly TA. New series of thiazole derivatives: Synthesis, structural elucidation, antimicrobial activity, molecular modeling and MOE docking. Molecules. 2019;24(9):1741.

7. Vernin G. The Chemistry of Heterocyclic Compounds.: Wiley. 1979.

8. Hantzsch A, Weber JH. Ueber verbindungen des thiazols (pyridins der thiophenreihe). Berichte Der Deutschen Chemischen Gesellschaft 1887;20(2):3118-32.

9. American Cancer Society. Atlanta. 2018

10. Das J, Chen P. Dasatinib as a potent pan-Src Kinase Inhibitor. J Med Chem. 2006;49(23).

11. Tricot G, Jayaram HN, Weber G, Tiazofurin HR. Biological Effects and clinical uses. Int J Cell Cloning. 1990;8(3):161-70.

12. Al-Saadi MS, Faidallah HM, Rostom SA. Synthesis and biological evaluation of some 2, 4, 5-trisubstituted thiazole derivatives as potential antimicrobial and anticancer agents. Arch Pharm Chem Life Sci. 2008;341(7):424-34

13. Amit C, Sheelmani AS, Payal C, Dhawan R. Chemistry of anticancer thiazole compounds. Chemistry. 2014 2014;2(1) 